JOSÉ M. TORRALBA. Libertad, objeto práctico y acción. La facultad del juicio en la filosofía moral de Kant. Georg Olms Verlag. Hildesheim-Zürich-New York (2009).

\title{
Òscar Cubo Ugarte
}

Presentamos un trabajo de enorme interés no sólo para los especialistas en la filosofía crítica de Kant, sino también para todo el público interesado por la filosofía de la acción en general. José María Torralba presenta en forma de libro los resultados de su investigación doctoral acerca de las distintas funciones que desempeña la facultad del juicio (Urteilskraft) en la filosofía práctica de Kant. Para ello, el Prof. Torralba divide su investigación en dos grandes bloques temáticos: el primero de ellos, compuesto por los dos primeros capítulos, lo dedica a investigar la especificidad de lo práctico en la filosofía kantiana, y el segundo, compuesto por los tres últimos capítulos, analiza con enorme detalle el papel que juega la facultad del juicio a la hora de aplicar e interpretar los dictámenes de la razón práctica. Desde nuestro punto de vista es en esta segunda parte de la obra donde se obtienen los resultados más importantes de la presente investigación, por lo que nos detendremos más pormenorizadamente en su presentación.

A lo largo del Capítulo I el Prof. Torralba se adentra con una suerte de efecto calidoscópico en la filosofía moral de Kant a través de un análisis minucioso de la noción kantiana de "causalidad por libertad», utilizando como hilo conductor el «Canon de la razón pura» de la Crítica de la razón pura y la Fundamentación de la metafisica las costumbres. Todo este análisis desemboca en el estudio de los principios prácticos que deben orientar la mencionada «causalidad por libertad», para que pueda recibir el calificativo de «moral». Especialmente sugerente resulta también el modo como en el Capítulo II se presenta la tesis kantiana de que no es la acción como tal, sino la máxima de la acción, es decir, el principio subjetivo de la acción, lo que debe ser enjuiciado como bueno o malo desde un punto de vista «moral». En cualquier caso, hay que resaltar que en este primer bloque temático del libro no sólo se analiza el concepto de libertad práctica en Kant, sino que se también el papel que desempeña la facultad del juicio práctico en la formación de las máximas subjetivas de la acción. A este respecto, el Prof. Torralba estudia los dos niveles de significación que tienen las máximas dentro de la filosofía práctica de Kant; y reformula de una manera muy suge- 
rente algunas reflexiones de especialistas como, por ejemplo J. Timmermann o M. Schwartz, acerca de la formación de máximas de "primer orden» y máximas de «segundo orden» (p. 145 y ss.) en relación con la facultad del juicio práctico.

Por lo que respecta al segundo bloque temático del libro, en él se analiza con gran detalle el papel que juega la facultad del juicio en la Crítica de la razón práctica y en la "Doctrina de la virtud» de la Metafísica de las Costumbres. Lo que el Prof. Torralba pone de relieve en el Capítulo III de su investigación es que en la Crítica de la razón práctica la facultad del juicio es fundamental para la constitución del objeto de la razón pura práctica como tal, es decir, para la constitución del «marco» normativo en el que es posible hablar de moralidad. Ahora bien, a pesar de que la facultad del juicio desempeña un importante papel para la constitución de la esfera trascendental de lo práctico, el autor del libro sostiene que a este nivel de la filosofía crítica todavía no se puede dar cuenta de la efectiva determinación de la causalidad del arbitrio «humano». Lo que el Prof. Torralba defiende es que en la segunda de las Críticas Kant elabora una cartografía a priori de la esfera de la acción moral, y saca a la luz las funciones puras y a priori de la facultad del juicio práctico, pero todavía no desciende, por así decirlo, al ámbito de las máximas concretas por las que se determina o se debe determinar el arbitrio humano. Dicho de otro modo, en el ámbito de la «Analítica de la razón pura práctica» queda establecido lo que una voluntad determinada moralmente podría adoptar como fundamento de determinación de su causalidad o aquello que podría querer en el caso de estar determinada por la moralidad. Con ello queda instituido el espacio o el «marco» normativo básico de la moralidad, pero se deja indeterminado el contenido de dicho marco y no se analiza todavía los deberes morales que resultan de la ley moral, ya que se trata del marco formal y a priori de la acción moral.

El estudio de los mencionados deberes morales se lleva a cabo en el Capítulo IV de la presente investigación, donde se tematizan los conceptos kantianos de antroponomía y eleuterología, tal y como aparecen en la Metafísica de las Costumbres. En esta última obra es donde Kant despliega los deberes positivos que se siguen de la ley moral al aplicarse a una naturaleza racional sensiblemente condicionada, como es la humana. A diferencia de la Crítica de la razón práctica en la Metafisica de las Costumbres sí que deviene un problema crucial la cuestión de la aplicación del principio de la moralidad a la naturaleza racional, pero sensiblemente condicionada, del hombre. En este sentido, el Prof. Torralba afirma 
que el programa moral kantiano no se agota con la crítica de la razón en su uso práctico, ya que tiene como una de sus principales tareas aplicarse a los seres humanos que son «imperfectamente» libres (p. 291)

Esta referencia a la finitud humana hace que sea necesario tematizar ciertos fines como deberes de la propia moralidad, lo cual implica a su vez un segundo nivel de tareas para la facultad práctica del juicio. Los «fines que son deberes» son aquellos fines que la ley moral prescribe a un ser racional sensiblemente condicionado. Estos fines son divididos por Kant en aquellos que conciernen a la "propia perfección» (deberes hacia sí mismo) y aquellos otros deberes que conciernen a la "felicidad ajena» (deberes hacia los demás). Ambos se derivan del principio supremo de la doctrina de la virtud, que Kant formula con las siguientes palabras: "obra según una máxima de fines tales que proponérselos pueda ser para cada uno una ley universal» (MS, Ak. VI 395). Todos estos deberes tienen como objetivo la progresiva moralización del ser humano, que debe convertirse en un ser plenamente racional. Como acertadamente señala el Prof. Torralba, la antroponomía de la que se habla en la Metafísica de las Costumbres no hace de la antropología el fundamento de la ética, sino que únicamente toma en consideración la naturaleza humana para el correcto ejercicio de la moralidad (p.373).

Por lo que respecta a las funciones que desempeña la facultad del juicio en la «Doctrina de la virtud» de la Metafísica de las Costumbres, el Prof. Torralba señala tres tareas fundamentales: la primera de ellas, es establecer los fines que son deberes, esto es, desplegar el sistema de los deberes a partir de la ley moral. Esta primera tarea la realiza la facultad del juicio en su «uso determinante», ya que de lo que se trata es de especificar el objeto correspondiente del arbitrio humano. La segunda tarea es distinguir en qué casos tienen aplicación los mencionados deberes y en cuáles no, para lo cual es necesario reflexionar sobre la relación que guardan las circunstancias concretas y aquello que prescribe la ley moral. Por último, la tercera y más importante tarea de la facultad práctica del juicio es responder a la pregunta: ¿qué debo hacer en cada caso? Para responder a esta pregunta es fundamental, según el Prof. Torralba, el «enjuiciamiento moral» y la «deliberación moral». El «enjuiciamiento moral» consiste en la comparación de la situación con el sistema de los deberes, con vistas a determinar cuál es la obligación que hay que cumplir en cada caso. A través de este «enjuiciamiento moral» se genera una "máxima subordinada" ( $M S$, Ak. VI 411) en la que se expresa la obligación que surge del deber. Sólo en casos excepcionales es necesaria la «deli- 
beración moral», a saber, en aquellos casos donde parece darse un dilema moral o un conflicto de deberes y es preciso reflexionar para determinar y establecer finalmente $e l$ deber (en singular) que surge de esa situación.

Junto a este exhaustivo análisis de las distintas funciones de la facultad del juicio práctico el Prof. Torralba dedica el último capítulo de su libro a investigar el fenómeno de la conciencia moral (Gewissen), puesto que también en el fenómeno de la conciencia moral juega un papel fundamental la facultad del juicio en su uso reflexionante. En este caso, la facultad del juicio no sólo se encarga de determinar si «algo es o no un deber» o de establecer el deber específico que se debe emprender en cada caso, sino que es la facultad responsable de sancionar los juicios morales que se emiten en cada caso. El análisis de la conciencia moral remite a la honestidad por parte del sujeto a la hora de juzgar la conformidad (o disconformidad) de sus máximas con la ley moral. Es decir, se trata de un juicio del sujeto sobre sí mismo, que depende de la sinceridad y de la veracidad del mismo. El Prof, Torralba entiende la conciencia moral como «la facultad del juicio que se juzga a sí misma» (Religion, Ak. VI 186) y, por tanto, en un sentido puramente reflexionante (véase, p. 378). Para fundamentar esta interpretación de la conciencia moral el Prof. Torralba recurre a algunos textos de la Religión dentro de los límites de la mera razón, la Metafísica de las Costumbres y las Lecciones de ética de Kant, en los que se pone de manifiesto que la conciencia moral no sólo es la encargada de sancionar el mencionado juicio «subjetivo», sino también la encargada de hacer que la voluntad siga aquello que está juzgando (sinceramente) como un deber moral.

Como conclusión, cabe destacar el rigor y la exhaustividad del presente estudio sobre la filosofía práctica de Kant. El Prof. Torralba consigue exponer con claridad los distintos sentidos que tiene lo "práctico» en la filosofía crítica de Kant, así como las distintas funciones y niveles de aplicación que adopta la facultad práctica del juicio en distintos lugares de la filosofía kantiana de la acción, pero sobre todo consigue poner de manifiesto la enorme riqueza y complejidad de la ética kantiana, que en ningún caso se puede reducir a un mero formalismo ético. De hecho, y como puede comprobar el lector del presente libro, la ética kantiana reflexiona precisamente sobre aquellos temas que nos afectan a cada uno de nosotros en la medida en que, como seres dotados de razón, tenemos que actuar en el mundo. 